\section{Glaucoma: fielding progressive disease}

ANANTH C. VISWANATHAN, ROGER A. HITCHINGS
The aim of glaucoma management is to prevent the development of clinically significant visual damage within the patient's lifetime, or to prevent significant worsening if damage has already occurred. In order to do this an estimate of the rate of visual deterioration must be made. This should be done using numerical analysis of a series of automated visual field tests, as human observers, even experienced ones, are not able to detect visual field progression reliably using clinical judgement alone. ${ }^{1}$ This measure of rate is a prerequisite if prevention of clinically significant visual damage is to be achieved, since it is through knowledge of the speed of deterioration that the degree of future loss of visual function may be anticipated. If the rate of visual field loss suggests that the patient will be visually disabled within their lifetime appropriate therapeutic measures should be instituted: effective lowering of intraocular pressure retards visual impairment ${ }^{2}$ even in normal-tension glaucoma. ${ }^{3,4}$ If, however, the rate of loss is close to the normal age-related decline in retinal sensitivity (about 1 decibel per decade $^{5}$ ) then the potentially sight-threatening complications of surgery and life-threatening complications of topical treatment may be avoided pending further review of the patient's visual function.

Methods of analysis that rely on detecting a significant change from baseline (event-type analyses) such as the Statpac $2^{6}$ and Delta ${ }^{7}$ programs do not provide a measure of rate of field loss and so only indicate that some deterioration has occurred in the past. It has been demonstrated that the most reliable estimates of progressive glaucomatous visual field decay are obtained by using a linear fit, i.e. postulating a constant reduction of sensitivity over time for each retinal location tested. ${ }^{8}$ This technique has been used for several years to investigate glaucomatous visual field change ${ }^{9,10}$ and has recently been re-examined. ${ }^{11-13}$ Pointwise linear regression detects visual field progression sooner than event-type analyses such as Statpac $2{ }^{14}$ demonstrates field loss undetected by summary measures of sensitivity (such as the mean defect value) and is a good predictor of the future behaviour of the field. ${ }^{3,8,15}$
Even sensitive, reliable methods such as pointwise linear regression are critically dependent on the frequency with which visual field tests are performed: progressive visual field loss cannot be detected unless it is adequately sought. When considering how often to measure the visual field of a glaucoma patient, factors such as the type of glaucoma, the number and results of previous tests, the age of the patient, recent changes in glaucoma therapy and the ability of the patient to produce reliable tests must be borne in mind. However, one of the commonest and most important reasons for repeatedly measuring visual fields is in order to detect progressive damage as early as possible. A recent study ${ }^{16}$ examined whether performing visual field tests once a year rather than three times a year would lead to a clinically significant delay in the detection of progressive glaucoma. The results were striking. Fewer than half the areas of visual field progression were detected when visual field tests were analysed only once a year. Furthermore, the 'once a year' strategy entailed a delay in recognition of progression of more than 1 year over a 4 year study period.

The advent of new perimetric strategies, such as the SITA algorithm, designed to reduce the time taken to perform a visual field test offers the prospect that glaucoma patients may be tested at each clinic visit rather than receiving an incomplete examination as they often do at present. This, coupled with assessments of the rate of visual field deterioration, the patient's age and general medical condition, the contribution of pathology other than glaucoma to visual impairment, and the patient's visual requirements will enable those who require treatment to obtain it promptly and those who do not to be spared unwanted side effects. Even with present-day perimetry, the increased use of resources implicit in performing visual field tests at least three times per year must be set against the wider financial, social and moral cost of allowing a potentially blinding disease to progress undetected.
A.C. Viswanathan R.A. Hitchings Moorfields Eye Hospital City Road London EC IV 2PD, UK 


\section{References}

1. Werner EB, Bishop KI, Koelle J, Douglas GR, LeBlanc RP, Mills RP, et al. A comparison of experienced clinical observers and statistical tests in detection of progressive visual field loss in glaucoma using automated perimetry. Arch Ophthalmol 1988;106:619-23.

2. Palmberg P. Epidemiology of POAG and rationale for therapy. Glaucoma Abstr 1969;6:10-23.

3. Bhandari A, Crabb DP, Poinoosawmy D, Fitzke FW, Hitchings RA, Noureddin BN. Effect of surgery on visual field progression in normaltension glaucoma. Ophthalmology 1997;104:1131-7.

4. Koseki N, Araie M, Shirato S, Yamamoto S. Effect of trabeculectomy on visual field performance in central 30 degrees field in progressive normaltension glaucoma. Ophthalmology 1997;104:197-201.

5. Heijl A, Lindgren G, Olsson J. Normal variability of static perimetric threshold values across the central visual field. Arch Ophthalmol 1987;105:1544-9.

6. Heijl A, Lindgren G, Lindgren A, et al. Extended empirical statistical package for evaluation of single and multiple fields in glaucoma: Statpac 2. In: Mills RP, Heijl A, editors. Perimetry update 1990/1991. Amsterdam: Kugler \& Ghedini, 1991:303-15.

7. Bebie $\mathrm{H}$, Fankhauser F. Delta manual. Schlieren: Interzeag AG, 1982.

8. McNaught AI, Crabb DP, Fitzke FW, Hitchings RA. Modelling series of visual fields to detect progression in normal tension glaucoma. Graefes Arch Clin Exp Ophthalmol 1995;233:750-5.
9. Noureddin BN, Poinoosawmy D, Fitzke FW, Hitchings RA. Regression analysis of visual field progression in low tension glaucoma. $\mathrm{Br} \mathrm{J}$ Ophthalmol 1991;75:493-5.

10. Poinoosawmy D, Wu J, Fitzke FW, Hitchings RA Discrimination between progressive and nonprogressive visual field loss in low tension glaucoma using MDT. In: Mills RP, editor. Perimetry update 1992/1993. Amsterdam: Kugler \& Ghedini, 1993:109-14.

11. Katz J, Gilbert D, Quigley HA, Sommer A. Estimating progression of visual field loss in glaucoma. Ophthalmology 1997;104:1017-25.

12. Wild JM, Hutchings N, Hussey MK, Flanagan JG, Trope GE. Pointwise univariate linear regression o perimetric sensitivity against follow-up time in glaucoma. Ophthalmology 1997;104:808-15.

13. Smith SD, Katz J, Quigley HA. Analysis of progressive change in automated visual fields in glaucoma. Invest Ophthalmol Vis Sci 1996;37:1419-28.

14. Viswanathan AC, Fitzke FW, Hitchings RA. Early detection of visual field progression in glaucoma: a comparison of PROGRESSOR and Statpac 2. Br J Ophthalmol 1997;81:1037-42.

15. Fitzke FW, Hitchings RA, Poinoosawmy D, McNaught AI, Crabb DP. Analysis of visual field progression in glaucoma. Br J Ophthalmol 1996;80:40-8.

16. Viswanathan AC, Hitchings RA, Fitzke FW. How often do patients need visual field tests? Graefes Arch Clin Exp Ophthalmol 1997;235:563-8. 